\title{
PERFORMANCE EVALUATION OF ARO-NDIZUOGU LOCAL CLAY IN ALKYD PAINT PRODUCTION
}

\author{
1,a, ${ }^{*}$ I. O. Igwe, ${ }^{2, b}$ C. M. Ewulonu, ${ }^{1, c}$ A. N. Chikei and ${ }^{1, d}$ B. Nicholas \\ ${ }^{1}$ Department of Polymer and Textile Engineering, Federal University of Technology, Owerri, \\ P. M. B. 1525, Owerri, Nigeria \\ ${ }^{2}$ Department of Polymer and Textile Engineering, Nnamdi Azikiwe University, Awka, P. M. B. 5025, \\ Awka, Nigeria \\ ${ }^{*}$ Corresponding author, Email: I. O. Igwe; zik3gh@gmail.com \\ azik3gh@gmail.com, bcm.ewulonu@unizik.edu.ng, 'an.chikei@gmail.com \\ and bnicholas@gmail.com
}

Keywords: Alkyd paint; Local clay; Viscosity; Adhesion; Drying properties; Film thickness

\begin{abstract}
The potentials of Aro-Ndizuogu clay as an extender in gloss paint have been investigated. The physical properties of the local clay investigated: refractive index (1.54), $\mathrm{pH}$ (7.10), oil absorption (32g/100g clay), and specific gravity (2.13) compared favourably with that of conventional extenders. Gloss paints were prepared using the local clay (as an extender), xylene as solvent, and alkyd resin as binder. Paint samples prepared using $\mathrm{TiO}_{2}$ pigment was used for comparison. Results obtained from the analysis of the paint samples showed that $\mathrm{TiO}_{2}$ formulated alkyd paint samples exhibited the highest specific gravity (1.42) while the alkyd paint containing 50 \% local clay, the least (1.30). While $\mathrm{TiO}_{2}$ formulated paint samples did not show any settling tendency, paint samples containing 50 and $60 \%$ local clay had poor settling tendencies. The resistance of dry paint films was generally good in $2 \% \mathrm{Na}_{2} \mathrm{CO}_{3}$, distilled water, and $2 \% \mathrm{NaCl}$. However, all the prepared paint samples failed $\mathrm{NH}_{3}$, and $\mathrm{H}_{2} \mathrm{SO}_{4}$ resistance tests. The present study has shown that Aro-Ndizuogu clay exhibited similar performance properties in the prepared alkyd paint samples like $\mathrm{TiO}_{2}$ prepared paint, and should find utilization in the surface coatings industry.
\end{abstract}

\subsection{Introduction}

In the current strive toward a sustainable future, renewable material resources are increasingly gaining attention and are being investigated for the development of future alternatives to conventional products. In this quest of sustainable materials for the coating industries, the potentials of Aro-Ndizuogu clays in alkyd paints are reported here. Each raw material in a coating formulation plays a significant role in deciding the performance of a coating system. Extenders, also referred to as extender pigments, are an integral part of almost all coating formulations, contributing significantly towards modifying various coating properties such as flow characteristics, gloss, abrasion resistance, setting tendency, etc [1]. They differ from true pigments since they do not impart opacity to the coating, and are practically transparent in the oil medium. The selection and proper blending of suitable extenders in paint help to optimize several engineering properties and aesthetics of a coating. Keeping pace with the technological advances in coatings, the technical demand on extenders has grown tremendously.

Extenders, in spite of their widespread use in almost all coatings and their elevation from "fillers" to "extenders" have received little attention from research scientists in the field of coating technology. Most of the extenders used in coatings are of mineral origin, and require long processing, including grinding, levigation, chemical treatments, etc, from one to final stage, resulting in significant loss of materials [2]. Available information indicates a yield of $75 \%$ in the processing of China clay and of $30 \%$ in the case of calcite [3]. Such extenders, and several other processed extenders are expensive leading to increase in cost of the resultant coating systems. Recently, paint formulators and technologists have begun to find technically, and economically viable extenders for use in coatings, 
and thus, bring down the cost of painting to acceptable limits. Some of the materials considered for extender purposes are reviewed below.

The use of red mud, a by-product of aluminum companies in protective coatings has been reported [4]. Several patented processes are available for the treatment of red mud particles for improve properties and for use in concrete formation [5]. The utilization of fly ash, a waste by-product of thermal power stations, as an extender in water based coating formulations has also been reported [6]. However, there were certain disadvantages that limited the use of fly ash in water based coatings [7]. The major problems associated with such coatings are their greater tendency towards increasing corrosion of the substrate material owing to the presence of water. The addition of surfactants to reduce the higher surface tension of water led to the formation of films with poorer water resistance. Further investigation, on the possibility of using fly ash as extenders in solvent borne coatings for high performance industrial applications has been reported [3]. The extender properties of fly ash were assessed, and compared with those of conventional extenders. The coatings that were developed showed improved corrosion and abrasion resistance and better resistance to chemicals. Saxena and Dhjimole [8] characterized and utilized copper tailing waste as an extender in paints. The waste is a siliceous material containing aluminum oxide, iron oxide and sulphate in significant concentrations. The sieved waste was characterized for basic extender properties like oil absorption, specific gravity, etc. Results obtained indicated that the developed extender was environmentally clean, and cost effective.

Yousseff et al [9] studied the possible utilization of silica waste fumes as an extender in paints. Silica waste fume is a by-product produced in the manufacture of ferrosilicon. Results obtained from the various paint formulations showed that silica fume can replace satisfactorily the imported diatomaceous silica from the economic and environmental point of view. Anyiam and Igwe [10] used industrial waste firebrick as an extender to formulate alkyd paints. Results showed similarity in the values of specific gravity and film thicknesses obtained for the waste clay, and commercial whiting formulated alkyd paint samples. The waste clay extended paint samples exhibited good viscosity properties. The use of an indigenous clay (Kaolin) from Mbano in Imo State, Nigeria as an extender in alkyd paints was reported by Odozi et al [11]. The performance characteristics of the indigenous clays in alkyd paint were reported to be comparable, and even marginally better than that of the imported, and commercial China Clay. Igwe and Ezeamaku [12] studied the use of two local clays, Amankwo Afikpo and Okposi, present in large quantities in Afikpo and Okposi LGAs of Ebonyi State, Nigeria as extenders in alkyd paints, and found that the formulated alkyd paints had good chemical resistance, and no adverse effect on other coating properties was reported.

In addition, the surface of kaolinite clays can be modified to improve their performance. Kaolin and metakaolin coated with layer of metal oxides have been studied [13] and the new composite materials were found to have interesting properties for use as pigment. The study on performance of local clay-titanium dioxide core-shell extender pigments in alkyd paints have shown that the new pigment combine the properties of both the clays and titanium dioxide, and have the potential to overcome their disadvantages [14]. Kaolin has also been used to prepare core-shell pigments containing ferrites and was found to be efficient as coating for protecting metal substrates [15]. In this regime of sustainable development, it is important to develop local raw materials for added value in line with the number 9 goal of the sustainable development goals (SDGs). This will ultimately generate employment for the local populace through the growth and development of small and medium enterprises (SMEs) that will engage in the mining and processing of the local clay thereby addressing SDGs 1 and 8. The present study in line with this goal, has demonstrated the performance of a local clay from Aro-Ndizuogu in alkyd paint samples. 


\subsection{MATERIALS AND METHODS}

\subsection{Materials}

Medium length soya bean oil-modified alkyd resin was used in this study as binder. It is a product of Nicen Chemical Industry Limited, Aba, Nigeria and has an acid value of $0.5 \mathrm{mgKOH} / \mathrm{g}$. resin. The local clays used were obtained from Aro-Ndizuogu in Imo State, Nigeria. Lead and cobalt naphthanate were used as driers in this study while xylene was used as the solvent.

\subsection{Preparation Clay Sample}

The Aro-Ndizuogu clay sample, hand dug from the clay deposit site, was first sun-dried and crushed. Impurities were removed from the clay after which it was calcined at $750{ }^{\circ} \mathrm{C}$. The calcined clay was sieved to $0.075 \mu \mathrm{m}$ particle size. The sieved clay was evaluated for hydrogen ion concentration (ASTM D 1208-96), specific gravity (ASTM D 153-84), refractive index (ASTM D 1208-96), and oil absorption (ASTM D 281-12).

\subsection{Preparation of Paint Samples}

A series of alkyd paints were prepared using the Aro-Ndizuogu clay, $\mathrm{TiO}_{2}$ and xylene. A typical formulation used in the preparation is shown in Table 1 . The weight ratio of the pigment and extender (clay) content to that of the binder solids content (known as the pigment to binder ratio, $\mathrm{P} / \mathrm{B}$ ) is calculated for the formulations, and it has a value of $0.3: 1.0$ for the paint samples. Cobalt and lead naphtanate dries were used as drying agents. The paint-drier mixtures was also prepared by accurately weighing out a given quantity of the prepared paint sample and calculated amounts of lead naphthanate and cobalt naphthanate driers were added. The paint-drier mixture was mixed thoroughly using a glass rod. The amount of driers added represents $0.50 \mathrm{wt} \%$ lead $(\mathrm{Pb})$, and $0.05 \mathrm{wt} . \%$ cobalt $(\mathrm{Co})$ which are the amount of these metals normally used in the surface coatings industry [16].

Table 1: Formulation of Alkyd Paint Samples

\begin{tabular}{|l|l|l|l|l|l|}
\hline \multicolumn{1}{|c|}{ Ingredients } & \multicolumn{5}{c|}{ Formulations, (g) } \\
\hline & I & II & III & IV & V \\
\hline Alkyd Resin & 147 & 147 & 147 & 147 & 147 \\
$\mathrm{TiO}_{2}$ & 48.2 & 38.6 & 28.9 & 24.1 & 19.3 \\
$\mathrm{Calcined} \mathrm{clay}_{\text {Solvent }}$ & 0 & 9.6 & 19.3 & 24.1 & 28.9 \\
Total Binder & 15 & 15 & 15 & 15 & 15 \\
Total Pigment & 487 & 147 & 147 & 147 & 147 \\
\hline
\end{tabular}

The American standard testing methods (ASTM) was used to evaluate the prepared alkyd paint samples for viscosity (ASTM D 1200-10), specific gravity (ASTM D1475-13), adherence to surface (ASTM D 6677-07, 2012), settling and skinning tendencies (ASTM D 869-85).

\subsection{Results and Discussions}

\subsection{Properties of Aro-Ndizogu Clay}

The specific gravity of the local clay was determined to be 2.13 . The specific gravity of some convectional extender pigments have been reported [17] to be: gypsum (2.34), quartz (2.80), china clay (2.60), calcium carbonate (2.55), and titanium dioxide (rutile) (4.2). The specific gravity of Titanium dioxide, a product of Sigma-Aldrich used in this study is 4.26. It is evident from the above result that $\mathrm{TiO}_{2}$, a prime pigment used for coating has a higher specific gravity than the local clay used in this study. The $\mathrm{pH}$ of the clay was determined to be 7.10. According to US Department of Agriculture on the classification of soil $\mathrm{pH}$ [18], the local clay is slightly alkaline. The $\mathrm{pH}$ of some extenders are: fly ash (8.15), talc (9-9.5), and Okigwe-Mbano clay (6.0). 
The spatula rub-out method was used to obtain the oil absorption of the clay which is $32 \mathrm{~g} / 100 \mathrm{~g}$ clay. The oil absorption of some extenders and pigments are: fly ash (19), barium sulphate (blanc fixed) (18.5), calcium carbonate (17.5), china clay (30), and talc (25 - 35). Less oil absorption by an extender indicates less resin demand without compromising other coating properties. The oil absorption depends mainly on the physical structure (i.e. size and shape of the extender particles), which also affects several other coating properties including flow characteristics, settling tendency, etc. The refractive index of the Aro-Ndizuogu clay was determined to be 1.57. It is important to know that all extenders have refractive indices that fall in the range, $1.45-1.65$, and which is not marked different from the value found in most dry paint films $(1.45-1.7)$. Therefore, extenders do not give either opacity or much color when they are added to the clear coatings. $\mathrm{TiO}_{2}$ is known to have refractive index near 2.75, which is higher than that of local clay. The refractive index of the extenders is: china clay (1.56) and calcium carbonate (whiting) (1.58). Thus, the refractive index of the local clay compared favorably with those of the important extenders used in coatings.

\subsection{Properties of Prepared Paint Samples}

\subsubsection{Specific Gravity}

The specific gravity of the prepared paint samples are given in Table 2. It is evident from the table that the paint sample formulated with $100 \% \mathrm{TiO}_{2}$ had the highest specific gravity when compared with those formulated using the local clays. This is to be expected since $\mathrm{TiO}_{2}$ has the highest specific gravity than the local clay. The lower specific gravities recorded for the local clay can be incorporated into the alkyd paints with considerate cost savings. Specific gravity of paints is used to determine the coverage of paint products on a substrate. The present study shows that there is no definite order of variation of specific gravity of the prepared paints with the amount of local clay incorporated into the paints.

\subsubsection{Paint Viscosity}

The viscosity of alkyd paint samples presented in Table 2 shows that $\mathrm{TiO}_{2}$ formulated paint exhibited the least viscosity, with paint sample containing $20 \%$ local clay having the highest viscosity. There is no definite order of variation of alkyd paint viscosities with the amount of local clay incorporated into the alkyd paints. The range of viscosities obtained in this study makes the prepared paint suitable for application by brush. The viscosity of any coating system is generally the result of interactions between its various constituents.

Table 2: Coating properties of prepared paint samples

\begin{tabular}{|c|c|c|c|c|c|c|c|c|}
\hline \multirow{2}{*}{$\begin{array}{c}\text { Formation } \\
\text { code }\end{array}$} & \multirow{2}{*}{$\begin{array}{l}\text { Specific } \\
\text { gravity }\end{array}$} & \multirow{2}{*}{$\begin{array}{c}\text { Viscosity } \\
\text { (poise) }\end{array}$} & \multirow{2}{*}{$\begin{array}{c}\text { Film } \\
\text { thickness } \\
(\mathbf{m m})\end{array}$} & \multicolumn{2}{|c|}{ Drying time (hr) } & \multirow{2}{*}{$\begin{array}{c}\text { Setting } \\
\text { test }\end{array}$} & \multirow{2}{*}{$\begin{array}{l}\text { Adherence } \\
\text { test }(\%)\end{array}$} & \multirow{2}{*}{$\begin{array}{c}\text { Skinning } \\
\text { test }\end{array}$} \\
\hline & & & & $\begin{array}{l}\text { Surface } \\
\text { dry }\end{array}$ & $\begin{array}{l}\text { Through } \\
\text { dry }\end{array}$ & & & \\
\hline T100 & 1.42 & 24.30 & 0.16 & 3 & 5.33 & 10 & 0 & $\begin{array}{l}\text { No skin } \\
\text { formed }\end{array}$ \\
\hline AR20 - T80 & 1.37 & 41.35 & 0.18 & 3.17 & 5.50 & 8 & 10 & " \\
\hline AR40 - T60 & 1.39 & 29.80 & 0.12 & 3 & 5.17 & 8 & 0 & " \\
\hline AR50-T50 & 1.30 & 36.61 & 0.19 & & 5.17 & 6 & 0 & " \\
\hline AR60 - T40 & 1.33 & 35.37 & 0.19 & & & 6 & 25 & “" \\
\hline
\end{tabular}

\subsubsection{Film Thickness}

As shown Table 2, the film thickness of alkyd paints prepared ranged from 0.15 to $0.20 \mathrm{~mm}$. The paint sample formulated with $40 \%$ local clay had the least film thickness of $0.12 \mathrm{~mm}$. The local clay formulated paint samples did not exhibit clear wet order on the variation of dry paint film thickness with clay contents. A film thickness of more than $20 \mu \mathrm{m}$ performs well as a barrier resistant to weathering [19]. The film thicknesses obtained for the dry paint films are in the desired range. 


\subsubsection{Drying Studies}

Table 2 shows that the prepared paint samples generally had surface dry periods of approximately 3 hours and through dry periods that range between 5 to 6 hours. According to Nigerian Industrial Standard, the surface dry period of an oil paint shall not exceed 6 hours from the time of application. Thus, all the prepared paint samples showed satisfactory surface drying properties. Interestingly, alkyd paints formulated with 50 and $60 \%$ local clays exhibited the least surface dry period, while $\mathrm{TiO}_{2}$ and alkyd paint containing $40 \%$ local clay had the same dry period of 3 hours. Thus, the local clay from Aro-Ndizuogu performed well in coatings when incorporated into alkyd paints at levels of $20-60 \%$ like the $\mathrm{TiO}_{2}$ paint.

\subsubsection{Settling Tendency and Skinning Tests}

The settling tests carried out on the prepared paint samples shown in Table 2 shows that $\mathrm{TiO}_{2}$ formulated paint sample did not exhibit any settling tendency. Paint samples formulated with 20 and $40 \%$ local clay exhibited slight tendency. However, paint samples containing 50 and $60 \%$ local clay exhibited settling tendency on storage for 2 weeks. Some properties of extenders/pigments affect their settling tendencies. These include particle size, particle shape, specific gravity, wetability, etc. The properties of the binder also affect the settling tendency of paints. The settling variations observed in this study may be attributed to differences in the particle structures of the clay and $\mathrm{TiO}_{2}$. None of the prepared paint samples exhibited any skinning tendency after storage for 2 weeks, thereby attesting to the good quality of the paints. Thus, the local clay formulated paints performed well in coating just like $\mathrm{TiO}_{2}$ paint.

\subsubsection{Adherence to Substrates}

The dry paint films exhibited good adherence properties (Table 2). A good oil paint should not exhibit more than $50 \%$ removal of the dried paint film. The paint sample $100 \% \mathrm{TiO}_{2}, 40$ and $50 \%$ local clays had excellent adherence property. The 10 and $25 \%$ film removal property recorded for paint samples containing 20 and $60 \%$ clay are in the desired range. The good adherence property recorded for the paint samples is an indication that the paints should function as anti-corrosion paints.

\subsubsection{Resistance to Chemicals}

The performance of the paint samples in various chemicals is shown in Table 3 and was rated according to the method of Muralidharan [20] as follows; 0 - No change; 1 - Very slight effect; 2 - Effect; 3 - Light effect; 4 - Definite effect; 5 - Bad effect. From the table, $2 \% \mathrm{Na}_{2} \mathrm{CO}_{3}$ and distilled water had no effect on dry paint films after immersion for half hour, and 24 hours respectively. All the prepared paint samples were adversely affected by $2 \% \mathrm{NH}_{3}$ solution. The dry paint film sample containing $60 \%$ local clay peeled out from $\mathrm{NH}_{3}$ solution. All the prepared paint samples performed poorly in $2 \% \mathrm{H}_{2} \mathrm{SO}_{4}$. Like was noted for $2 \% \mathrm{NH}_{3}$ solution, the sample generally exhibited color change, shrinkage and peelings. The dry films of the formulated paint sample surprisingly performed well in $2 \% \mathrm{NaCl}$; indication that these paints could function as anticorrosive paints. The paint sample formulated using $40 \%$ local clay exhibited slight peeling effect in $2 \% \mathrm{NaCl}$. 
Table 3: Resistance of Dry Paint Films to Chemicals

\begin{tabular}{|c|c|c|c|c|c|}
\hline \multirow[b]{2}{*}{$\begin{array}{l}\text { Formulation } \\
\text { code }\end{array}$} & \multicolumn{5}{|c|}{ Performance Rating/Quality Effect } \\
\hline & $\begin{array}{c}2 \% \\
\mathrm{Na}_{2} \mathrm{CO}_{3}\end{array}$ & $2 \% \mathrm{NH}_{3}$ & $\begin{array}{c}\text { Distilled } \\
\text { water }\end{array}$ & $2 \% \mathrm{H}_{2} \mathrm{SO}_{4}$ & $2 \% \mathrm{NaCl}$ \\
\hline $\mathrm{T} 100$ & 0 & $\begin{array}{l}4 \\
\text { (slight shrinkage and light } \\
\text { color change to brown) }\end{array}$ & 0 & $\begin{array}{l}5 \\
\text { (slight peeling and } \\
\text { shrinkage) }\end{array}$ & 0 \\
\hline AR20 - T80 & 0 & $\begin{array}{l}4 \\
\text { (shrinkage and slight } \\
\text { change of color to brown) }\end{array}$ & 0 & $\begin{array}{l}5 \\
\text { (Slight peeling and } \\
\text { shrinkage) }\end{array}$ & 0 \\
\hline AR40 - T60 & 0 & $\begin{array}{l}4 \\
\text { (Slight peeling, shrinkage } \\
\text { and color change to brown) }\end{array}$ & 0 & $\begin{array}{l}5 \\
\text { (Slight peeling and } \\
\text { shrinkage) }\end{array}$ & 0 \\
\hline AR50 - T50 & 0 & $\begin{array}{l}4 \\
\text { (Slight shrinkage, color } \\
\text { change go brown) }\end{array}$ & 0 & $\begin{array}{l}5 \\
\text { (Slight color change } \\
\text { to brown, peeling } \\
\text { and shrinkage) }\end{array}$ & 0 \\
\hline AR60 - T40 & 0 & $\begin{array}{l}\text { Peel out, shrinkage and } \\
\text { brown color observed }\end{array}$ & 0 & $\begin{array}{l}5 \\
\text { (color changed to } \\
\text { brown, shrinkage, } \\
\text { peeled out) }\end{array}$ & 0 \\
\hline
\end{tabular}

\subsection{Conclusions}

The local clay obtained from Aro-Ndizuogu, Imo State, Nigeria, has been used successfully to prepare alkyd paint with improved performance characteristics. The $\mathrm{TiO}_{2}$ formulated paint sample has the highest specific viscosity value with the specific gravity of the local clay formulated paints in the range 1.30-1.40. The local clay formulated paint sample containing $20 \%$ local clay exhibited the highest paint viscosity while $\mathrm{TiO}_{2}$ formulated paint sample, the least. The film thickness of the formulated paint samples where in the range, 0.10-0.20. The surface dry periods of the paint samples were generally three hours and good. Similarly, all the prepared paint samples had through dry periods between 5.0-6.0 hours. The adherence of the prepared paint samples was generally good. While the prepared paint samples did not show any skinning tendency, the local clay formulated paint samples exhibited various settling tendencies. $\mathrm{TiO}_{2}$ formulated paint sample did not show any settling tendency. The resistance of the dry paint films was generally good in $20 \%$ $\mathrm{NaCl}$. However, all the paint samples failed $\mathrm{NH}_{3}$ and $\mathrm{H}_{2} \mathrm{SO}_{4}$ resistance tests. The present study has highlighted utility of local clay obtained from Aro-Ndizuogu in formulating alkyd paint. Ten samples prepared using the local clays generally exhibited good performance properties just like $\mathrm{TiO}_{2}$ formulated paint samples. It is the opinion of the authors that paint industries should exploit the possibilities of using Aro-Ndizuogu clay in paint productions. The present study has shown that all the prepared paint samples failed $\mathrm{NH}_{3}$ and $\mathrm{H}_{2} \mathrm{SO}_{4}$ resistance tests. It is therefore recommended that more research should be carried out on ways of improving the resistance of the prepared paints in this media. Judging from the outcome of the present study, the prepared paint samples should not be used in ammonia and sulphuric acid prone environments.

\section{Reference}

[1] R. Woodridge, Principles of paint formulation, Blackie Academic \& Professional, New York, 1991.

[2] W.M. Morgans, Outlines of paint technology. Edward Arnold, London, 1990.

[3] S. Tiwari, M. Saxena, Use of fly ash in high performance industrial coatings. British Corrosion Journal, 34(3), (1999) 184-191.

[4] P.Vassiliou, T. Argyropoulos, Red mud as anticorrosive pigment for metal protective organic coatings, 5th international exhibition and conference on environment (HELECO '05), Athens, Greece, (2005). 
[5] R.S. Thakur, S.N. Das, Red mud: Analysis and utilization. Publications and Information Directorate, Wiley, New Delhi, (1994) 195-200.

[6] B.B. Gogte, A. Agrawal, Fly ash based coatings. Paintindia XLIV (10), (1994) 51-56

[7] Z.W.Wicks, F.N. Jones, S.P. Pappas, D.A. Wicks, Organic coatings: Science and Technology 3rd ed. John Wiley and sons Inc., New Jersey, USA, 2007.

[8] M. Saxena, L.K. Dhimole, Utilization and value addition of copper tailing as an extender for development of paints. Journal of Hazardous Materials, 129(1-3), (2005) 50-57.

[9] E.A.M. Youssef, Characterization, surface modification, and evaluation of Egyptian dolomite ore as an extender pigment for paint. Journal of Pigment and Resin Technology, 31(4), (2002) 226-233.

[10] C.K. Anyiam, I.O. Igwe, Studies on the use of an industrial waste clay in alkyd paint formulations. International Journal of Academic Research, 4(2), (2012) 15-23.

[11] T.O. Odozi, R. Dore, C.O. Onu, Paint extenders based upon indigenous clay. Journal of Nigeria Society of Chemical Engineers, 5 (2), (1986) 34-40.

[12] I.O. Igwe, L.U. Ezeamaku, The use of some local clays in alkyd paint formulations. Malaysian Polymer Journal, 5(1), (2010) 81-94.

[13] V. Šteng1, D. Popelková, T.M. Grygar, Composite pigments based on surface coated kaolin and metakaolin. Applied Clay Science, 101, (2014) 149-158.

[14] C.M. Ewulonu, I.O. Igwe and G.N. Onyeagoro, Performance of local clay-titanium dioxide core-shell extender pigments in alkyd paints. Advances in Nanoparticles, 5, (2016) 90-102, http://dx.doi.org/10.4236/anp.2016.51011

[15] N.M. Ahmed, W.M. Abd El-Gawad, E.A. Youssef , E.R. Souaya, New eco-friendly anticorrosive core-shell pigments. Pigment \& Resin Technology, 44 (5), (2015) 276 - 291, http://dx.doi.org/10.1108/PRT-10-2014-0085

[16] J.V. Koleske, Driers and Metailc Soaps, In, J. V. Koleske (ed.), Paint and coating testing manual: Fourteenth edition of the Gardner-Sward Handbook. ASTM, Philadelphia, USA. 1995.

[17] C.M. Ewulonu, I.O. Igwe, G.N. Onyeagoro, Synthesis and Characterization of Local Clay Titanium Dioxide Core-Shell Extender Pigments, Journal of Coatings Technology and Research, Accepted, (2016), DOI: 10.1007/s11998-016-9786-4.

[18] Soil Survey Division Staff (1993). Soil survey manual 1993: Chapter 3, selected chemical properties. Soil conservation service. USA department of agriculture handbook. Retrieved 2011-03-12 from (http://soils.usda.gov/technical/manual/contents/chapter3.html).

[19] D. Tan Tian Aik, Durability and $\mathrm{TiO}_{2}$ pigments, 1995 Paintindia Annual, (1995) 84 -93.

[20] N.M. Muralidharan, K.G. Unnikrishnan, M. Unnikrishnan, C.S.B. Nair, Utilization of rubber seed oil and karinnota oil for the preparation of air drying oil modified alkyd resin. Paintindia, 31(5), (1981) $5-9$. 